\title{
Al margen del tiempo Deseos, ritmos y atmósferas en el cine argentino
}

\section{PAZESCOBAR}

escobar.pax@gmail.com_Universidad Nacional de la Patagonia y Consejo Nacional de Investigaciones Científicas y Técnicas, Argentina.

ORCID: https://orcid.org/0000-0003-2022-1903

CÓMO CITAR: Escobar, P. (2021). Al margen del tiempo. Deseos, ritmos y atmósferas en el cine argentino. InMediaciones de la Comunicación, 16(1), 211-217. DOI: http://doi.org.10.18861/ ic.2021.16.1.3104

Fecha de recepción: 1 de noviembre de 2020

Fecha de aceptación: 12 de diciembre de 2020

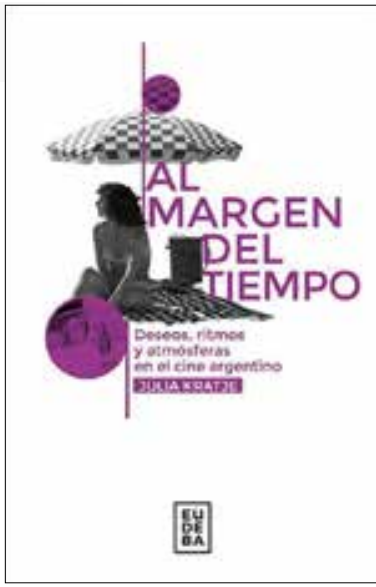

Kratje, J. (2019). Al margen del tiempo. Deseos, ritmos y atmósferas en el cine argentino. Buenos Aires: EUDEBA.

\section{RESUMEN}

Al margen del tiempo. Deseos, ritmos y atmósferas en el cine argentino de Julia Kratje tiene dos puntos de partida posibles: 1) la necesidad académica y política de reflexionar sobre cómo el tiempo se experimenta de forma desigual en razón de la pertenencia de clase y de género; 2) la sospecha de que ciertas películas argentinas ponen en tensión regímenes de visibilidad androcéntricos a partir de la puesta en escena de otros usos del tiempo, por donde se cuelan la posibilidad del ocio y del goce. El interés general del libro es explorar en algunas poéticas del cine argentino contemporáneo, sus modos de proponer otras territorialidades, otras temporalidades, otros mundos afectivos y, por ende, otros vínculos. Si el orden heteronormativo, patriarcal y capitalista pretende imponer un ritmo homogéneo a todos los cuerpos, Kratje propone entender al ocio no como el complemento de ese impuesto ritmo único, sino como una forma de resistencia que potencialmente permitiría cierta autonomía.

PALABRAS CLAVE: cine argentino, tiempo, atmósferas, género.

\begin{abstract}
Al margen del tiempo. Deseos, ritmos y atmósferas en el cine argentino [Outside time. Desires, rhythms and atmospheres in argentine cinema] of Julia Kratje has two possible starting points: 1) the political and academic need to reflect upon the way in which time is unequally experienced according to social class and gender;2) the conjecture that someargentine filmsdisruptandrocentric regimes of visibility through the staging of other uses of time, where it appears the possibility of leisure time and pleasure. The general purpose of the book is to explore some of the aesthetic principles of argentine contemporary cinema, its way of proposing other territorialities, other temporalities, other manners of affection and, thus, other bonds. If the heteronormative, patriarchal, capitalist order expects to impose a homogeneous rhythm to all of the bodies, Kratje proposes to see leisure not as the complement of this imposed, unique rhythm but as a way of resistance that would potentially create some autonomy.
\end{abstract}

KEYWORDS: Argentine cinema, time, atmospheres, gender. 


\section{RESUMO}

Al margen del tiempo. Deseos, ritmos y atmósferas en el cine argentino [À margem do tempo. Desejos, ritmose atmosferasnocinemaargentino] de Julia Kratjetêm dois pontos de partida possíveis: 1) a necessidade acadêmica e política de refletir sobre como o tempo é vivido de forma desigual devido ao pertencimento de classe e gênero; 2) a suspeita de que certos filmes argentinos tensionam regimes de visibilidade androcêntricos a partir da encenação de outros usos do tempo, por onde permeiam a possibilidade delazer efruição. Ointeresse geral do livro é explorar em algumas poéticas do cine- ma argentino contemporâneo, suas formas de propor outras territorialidades, outras temporalidades, outros mundos afetivos e, portanto, outros vínculos. Se a ordem heteronormativa, patriarcal e capitalista pretende impor um ritmo homogêneo a todos os corpos, Kratje propõe entender o lazer não como um complemento de esse ritmo único imposto, mas sim como uma forma de resistência que potencialmente permitiria alguma autonomia.

PALAVRAS-CHAVE: cinema argentino, tempo, atmosferas, gênero. 


\section{AL MARGEN DEL PAPER: UN RITMO Y UN DESEO PROPIOS}

Tal como las películas que Julia Kratje analiza en su libro, que escapan a la linealidad temporal y a las lógicas causales, en Al margen del tiempo. Deseos, ritmos y atmósferas en el cine argentino no importa demasiado cuál es la motivación primera: si la necesidad académica y política -es decir intelectual- de reflexionar sobre cómo el tiempo se experimenta y se vive de forma no sólo diferente, sino también desigual en razón dela pertenencia de clasey de género; o si fue la sospecha de que en ciertas películas contemporáneas del cine argentino-no casualmente dirigidas mayoritariamente por mujeres-sus estrategias estilísticas, elecciones narrativas y lugares de enunciación ponen en tensión ciertos regímenes de visibilidad androcéntricos (por realizar una clasificación rápida) y permiten disidentes configuraciones sensibles a partir de la puesta en escena de otros usos del tiempo, por donde-como el agua de tres delas películas analizadas- se cuelan la posibilidad del ocio y del goce.

Sin embargo, cuál fue la motivación primera no tiene importancia. A igual que el film Rompecabezas dirigido por Natalia Smirnoff (2009), analizado en la segunda parte de Al margen del tiempo, la coherencia y la unicidad de este libro no dependen del orden en el que se ubican las diferentes partes. Dehecho, admitiría otro orden sin que por eso se altere la profundidad y la coherencia de un análisis que, también, como las películas sobre las que se reflexiona, logra hacer primerísimos primeros planos de aquellos elementos que, sin la mirada escudriñadora de Kratje, seguramente hubiéramos pasado por alto. Y que son justamente aspectos, imágenes, acciones, disposiciones corporales, afectos poco o nada representados por el cine industrial. Estas imágenes-sonidos, no tanto al margen como marginados, adquieren posibles sentidos en un todo constituido por claves de lectura e hipótesis que otorgan cohesión a la indagación de Kratje. La autora pone en diálogo y establece posibles puentes y cruces, sin por ello homogeneizar ni perder de vista las particularidades y las diferencias de las poéticas de cada película.

El interés general del libro es explorar -e implícitamente ensanchar los horizontes de la imaginación política- en cierto tipo de cine; la construcción de otras territorialidades, temporalidades alternativas, otros mundos afectivos y, por ende, otros vínculos. Si el orden heteronormativo, patriarcal y capitalista pretende imponer un ritmo homogéneo a todos los cuerpos, en Al margen del tiempo Kratje propone entender al ocio no como el complemento de ese impuesto ritmo único, sino como una forma de resistencia que potencialmente permite cierta autonomía. En sus propios términos se pregunta si podremos concebirlo "como una experiencia que habilita posicionamientos subjetivos renovados" (Kratje, 2019, p. 18). Se trata de pensar al cine, en su acepción contraria al espectáculo - para seguir a Jean Louis Comolli (2010)-, como creador de atmósferas propicias parala visibilización de "otros sujetos, vínculos sociales y repartos sensibles" (Kratje, 2019, p. 90). 
El libro se estructura en partes bien diferenciadas que dialogan y se complementan entre sí, pero que podrían leerse como ensayos autónomos. En la primera parte, titulado "Otras territorialidades", estudia las películas: Ana y los otros (Murga, 2003), Una novia errante (Katz, 2006) y Ostende (Citarella, 2011), que ponen en escena las experiencias de desplazamientos de personajes femeninos por espacios abiertos, como habilitantes de otros usos del tiempo $\mathrm{y}$-potencialmente- del goce en sus múltiples manifestaciones, para dar cuenta de (otras) subjetividades deseantes (que contrarían los mandatos de un capitalismo heteropatriarcal siempre superyoico).

En la segunda parte, a la que titula "Otras temporalidades", Kratje analiza las películas Rompecabezas (Smirnoff, 2009), Réimon (Moreno, 2014) y La niña santa (Martel, 2004). Aquí observa cómo se renuevan los usos y el propio sentido del tiempo, y su relación con el goce (de nuevo, como cuestionador del tiempo productivo y reproductivo del capital) en espacios interiores, en general vinculado a lo doméstico todavía hoy asociado binariamente a las femineidades. Según la propia autora, estas narraciones "conmocionan el reparto de los tiempos desde los interiores" (Kratje, 2019, p. 19). O, dicho de otro modo, ensanchan nuestra percepción e imaginación a otras realidades posibles al proponer modos alternativos de habitary ser en los espacios domésticos/privados.

Entre estas dos partes, Kratje nos presenta el capítulo titulado "Interludio", que podría asociarse a "Las playas del cine" sobre las que reflexiona la autora: "Ese lugar intersticial entre el continente y el océano, entre cultura y naturaleza. [Con] un horizonte infinito [y] límites desdibujados" (Kratje, 2019, p. 66). Decimos que son como las playas porque este "Interludio" se encuentra entre las dos partes principales del libro, y también explicita las relaciones entre lo fílmico y lo extra-fílmico, entre historia del cine e historia social, entre campo estético y sociocultural, entre ficción(es) y lo real (con los diferentes sentidos que esto pueda tener), entre percepción y política, entre tiempo(s) y espacio(s). Colocada en ese umbral (Bajtín, 2011), la autora despliega herramientas analíticas y conceptuales profusa y profundamente fundamentadas para dar cuenta de las claves de lecturas que, si bien son diferentes y provenientes de diferentes campos de saber para cada película, colaboran para comprender dialógicamente ciertas poéticas del cine contemporáneo y las coordenadas socioculturales que se expresan de manera sintomática en él. Para Kratje el estudio de las atmósferas colabora para pensar el cine desde perspectivas históricas y pluridimensionales.

Entonces, si en parte del cine argentino actual -en consonancia con un cine continental- lo político está en las imágenes expresando sensibilidades que permiten otras configuraciones sensibles y sociales, focalizar la atención en la atmósfera permite figurar la imprevisibilidad y autonomía de los deseos. Figuraciones que hacen parte de las mutaciones que los feminismos y los movimientos socio-sexuales visibilizaron -y disputaron- en el espacio público 
y en las agendas políticas. Kratje revisa algunas corrientes teóricas feministas puestas en diálogo con las nociones de stimmung -como tonos, humores, estados afectivos que no se localizan ni en la interioridad ni en el mundo, sino en el límite entre ambos-y de idiorritmia-resumido por David Oubiña "como ritmo del deseo frente a la configuración represiva de la cadencia dominante" (Oubiña en Kratje, 2019, p. 12)-. Este recorrido, sumado a la atención a la propia materialidad de las películas, le permite proponer la noción de atmósfera generizada, o sea, un estado, tono, clima afectivo o humor que exhibe "las marcas sexuadas del discurso audiovisual” (ob. cit., p. 13). Estas atmósferas generizadas dan cuenta de cómo el entorno físico y el social condicionan las estructuras de sentimientos y, más concretamente, pueden pensarse como huellas de experiencias en los vínculos desiguales entre varones, mujeres y otras corporalidades siempre en intersección o co-constituidas por las desigualdades de clase y la racialización. La habilidad está, entonces, en poder pensar cómo aparecen en la imagen-sonido.

Los films analizados están des-centrados del androcentrismo y del cine industrial. Y el libro Al margen del tiempo, como las películas que allí habitan a contratiempo de varios centrismos, contradice la estructura académica del paper. E, indirectamente, esta estructura espiralada del texto, por la cual se puede ir y volver, también se opone a la linealidad temporal de la escritura causal impuesta por la racionalidad científica de la todavía tan androcéntrica como occidentalizada academia argentina. Ya sabemos, por ejemplo, gracias a Walter Benjamin (2019), lo clave que es oponerse al tiempo lineal-causal (ese tiempo vacío y homogéneo como lo definía el filósofo y político alemán) si se quiere proponer alguna dimensión contrapuesta a la lógica del capital (colonial yheteronormado, además). Combatir esa noción de tiempo era para Benjamin una condición sine quanon para ensanchar la imaginación política y pensar de forma realmente alternativa.

Al margen del tiempo admite ser leído en diferente orden, no se subsume a la cadencia impuesta por las estructuras rígidas de la escritura académica y por eso constituye un ensayo polifónico, tan apasionado como riguroso. Con Eduardo Grüner (2013) podríamos decir que es un ensayo, en tanto género culpable porque no es tan inter o transdisciplinar como indisciplinado: recurre a la historia del cine argentino y mundial, establece genealogías fílmicas autorales, genéricas, temáticas y estilísticas, abreva en teorías fílmicas, feministas y fílmicas feministas, acude a la teoría musical y a la literatura, permitiéndole establecer o detectar intertexualidades de diversos tipos. Logra hacer de la interpretación un ejercicio gozoso o, para usar una noción de la misma Kratje, una pasión desapegada. La cinefilia aquí no va en contra de la rigurosidad del análisis, sino que parece dar carnadura a la idea de que se "disfruta de aquello que se conoce, y sólo se conoce aquello que es posible comprender" (Carmona, 1991, p. 10). El libro de Kratje hace gala de lo que, en realidad, 
entraña todo discurso: la heteroglosia, esa apertura a la participación de dos o más voces, la existencia de diversas perspectivas con las que construimos nuestros enunciados.

Finalmente, leer este libro constituye una experiencia que no solo nos (con) mueve a reflexionar sobre el tiempo, como construcción y como noción fundamental que toda imaginación política debe contemplar para construir otros mundos posibles (con otros afectos, otras sensibilidades yotros vínculos). Además, la conjunción entre minuciosidad analítica y pasión por el cinelogra hacer de esa zona de encuentro una experiencia de lectura arduamente reflexiva y, también, profundamente sensorial, tanto visual como sonora, incluso háptica. La sensación es que podemos, ahora munidxs con las herramientas dela crítica, sumergirnos y bucear en las múltiples capas polivalentes y plurisignificantes que tienen estas (yotras) películas, capaces de sacudir nuestros modos habituales (o habituados) de percibir el mundo. Quizá, incluso, podríamos arriesgar que el libro de Kratje contribuye indirectamente a eso que anhela la cineasta Lucrecia Martel: “Cualquier distorsión de la percepción -esta es mi ilusión enfermiza-lo que genera es un disturbio en el entornoy eso permite quizá, no digo siempre, otra manera de concebir la realidad" (Martel en Kratje, 2019, p. 154).

\section{REFERENCIAS}

Bajtín, M. (2011). Estética de la creación verbal. Buenos Aires: Siglo XXI.

Benjamin, W. (2019). Iluminaciones. Buenos Aires: Taurus.

Carmona, R. (1991). Cómo se comenta un texto fílmico. Cátedra: Madrid.

Comolli, J. L. (2010). Cine contra espectáculo seguido de Técnica e ideología: 1971-1972. Buenos Aires: Manantial.

Grüner, E. (2013). Un género culpable. La práctica del ensayo: entredichos, preferenciase intromisiones. Buenos Aires: Godot.

Kratje, J. (2019). Al margen del tiempo. Deseos, ritmos y atmósferas en el cine argentino. Buenos Aires: EUDEBA.

\section{MATERIAL AUDIOVISUAL CITADO}

Citarella, L. (2011). Ostende. Argentina: Universidad del cine y El pampero cine.

Katz, A. (2006). Una novia errante. Argentina: Flehner Films.

Martel,L. (2004). La niña santa. Argentina-España-Reino Unido-Italia:ElDeseo, Senso Producciones, La Pasionaria, R\&C Produzioni y Teodora. 
Moreno, R. (2014). Réimon. Argentina-Alemania: Compañía amateur, Rohfilm y Universidad del cine.

Murga, C. (2003). Ana y los otros. Argentina: Stardis Pictures.

Smirnoff, N. (2009). Rompecabezas. Argentina-Francia: Carrousel films y Zarlek producciones.

* Contribución: $100 \%$ de la autora.

* Nota: el Comité Editorial de la revista aprobó la publicación de la reseña.

\section{(c) BY}

Artículo publicado en acceso abierto bajo la Licencia Creative Commons - Attribution 4.0 International (CC BY 4.0).

\section{IDENTIFICACIÓN DE LAAUTORA}

Paz Escobar. Doctora en Historia, Universidad Nacional de La Plata (Argentina). Licenciada en Historia, Universidad Nacional de la Patagonia (Argentina). Beca posdoctoral, Consejo Nacional de Investigaciones Científicas y Técnicas de Argentina. Docente e Investigadora, Facultad de Humanidades y Ciencias Sociales, Universidad Nacional de la Patagonia. Integrante, Asociación Argentina de Estudios sobre Cine y Comité Editorial de la revista Imagofagia. Como docente está enfocada en proponer una perspectiva feminista para el estudio de la historia y en aportar a la utilización de la audiovisualidad como fuente y objeto de estudio de la historia. Autora del libro Cine e Historia la Patagonia en imágenes, 1936-1976 (2011). Publicó artículos en revistas especializadas de Argentina, Chile, Estados Unidos, Francia y Alemania. 
(N) 